Delft University of Technology

\title{
Climate-driven seasonal geocenter motion during the GRACE period
}

Zhang, Hongyue; Sun, Yu

DOI

10.1007/s11600-018-0130-5

Publication date

2018

Document Version

Final published version

Published in

Acta Geophysica

\section{Citation (APA)}

Zhang, H., \& Sun, Y. (2018). Climate-driven seasonal geocenter motion during the GRACE period. Acta Geophysica, 66(2), 223-232. https://doi.org/10.1007/s11600-018-0130-5

\section{Important note}

To cite this publication, please use the final published version (if applicable).

Please check the document version above.

\section{Copyright}

Other than for strictly personal use, it is not permitted to download, forward or distribute the text or part of it, without the consent of the author(s) and/or copyright holder(s), unless the work is under an open content license such as Creative Commons.

\section{Takedown policy}

Please contact us and provide details if you believe this document breaches copyrights.

We will remove access to the work immediately and investigate your claim. 


\title{
Climate-driven seasonal geocenter motion during the GRACE period
}

\author{
Hongyue Zhang ${ }^{1,2} \cdot$ Yu Sun ${ }^{3,4}$ \\ Received: 13 October 2017 / Accepted: 16 March 2018 \\ (C) Institute of Geophysics, Polish Academy of Sciences \& Polish Academy of Sciences 2018
}

\begin{abstract}
Annual cycles in the geocenter motion time series are primarily driven by mass changes in the Earth's hydrologic system, which includes land hydrology, atmosphere, and oceans. Seasonal variations of the geocenter motion have been reliably determined according to Sun et al. (J Geophys Res Solid Earth 121(11):8352-8370, 2016) by combining the Gravity Recovery And Climate Experiment (GRACE) data with an ocean model output. In this study, we reconstructed the observed seasonal geocenter motion with geophysical model predictions of mass variations in the polar ice sheets, continental glaciers, terrestrial water storage (TWS), and atmosphere and dynamic ocean (AO). The reconstructed geocenter motion time series is shown to be in close agreement with the solution based on GRACE data supporting with an ocean bottom pressure model. Over $85 \%$ of the observed geocenter motion time series, variance can be explained by the reconstructed solution, which allows a further investigation of the driving mechanisms. We then demonstrated that $\mathrm{AO}$ component accounts for 54,62, and $25 \%$ of the observed geocenter motion variances in the $X, Y$, and $Z$ directions, respectively. The TWS component alone explains 42,32 , and $39 \%$ of the observed variances. The net mass changes over oceans together with self-attraction and loading effects also contribute significantly (about 30\%) to the seasonal geocenter motion in the $X$ and $Z$ directions. Other contributing sources, on the other hand, have marginal (less than 10\%) impact on the seasonal variations but introduce a linear trend in the time series.
\end{abstract}

Keywords Geocenter motion · Mass transportation · GRACE $\cdot$ Degree 1 coefficients

\section{Introduction}

Geocenter motion is usually defined as the relative movement of the center-of-mass (CM) of the entire Earth system with respect to the center-of-figure (CF) of the solid Earth surface (e.g., Petit and Luzum 2010; Ray 1999). Its nontidal portion is primarily driven by redistributing masses both on the Earth's surface and inside the solid Earth. Detectable solid Earth contributions including those due to glacial isostatic adjustment (GIA) and very large

\section{Yu Sun}

jade.yusun@outlook.com

1 Institute of Remote Sensing and Digital Earth, Chinese Academy of Sciences, Beijing, China

2 University of Chinese Academy of Sciences, Beijing, China

3 Key Lab of Spatial Data Mining and Information Sharing of Ministry of Education, Fuzhou University, Fuzhou, China

4 Geoscience and Remote Sensing Department, Delft University of Technology, Delft, The Netherlands earthquakes only affect the linear trend estimates of the geocenter motion time series. Mass changes in the Earth's outer fluid layers, such as atmosphere, oceans, terrestrial water, glaciers, and ice sheets, are responsible for both seasonal and linear variations in the geocenter motion time series.

In the $\mathrm{CF}$ reference frames, geocenter motion is equivalent to the degree 1 terms $\left(C_{10}, C_{11}\right.$, and $\left.S_{11}\right)$ of the temporal variations of the gravity field. It can be determined with traditional geodetic techniques such as the satellite laser ranging (SLR), the global navigation satellite system (GNSS), and the Doppler orbiography and radiopositioning integrated by satellite (DORIS). These techniques are called direct methods, since they use ground tracking stations anchored to the solid Earth to observe satellites orbiting about the $\mathrm{CM}$ and can directly build a link between the CM and the CF (e.g., Cheng et al. 2013; Meindl et al. 2013; Feissel-Vernier et al. 2006). However, the quality of the corresponding products is limited by the deficiency in modeling the satellite dynamics and the socalled network effect. The network effect affects all direct 
methods, since the employed ground tracking networks are sparse or not evenly distributed that they are realizing the center-of-network $(\mathrm{CN})$ rather than the $\mathrm{CF}$ (Wu et al. 2003). It is reported recently that the network effect can be as large as the geocenter motion itself (Zannat and Tregoning 2017a, b). Geocenter motion can also be inverted if the global solid Earth deformation is measured at GPS sites (Blewitt et al. 2001). This is because the translation of the geocenter is always companioned with a unique degree 1 load induced solid Earth deformation (Blewitt 2003). Other variants of the GPS inversion method are emerged to overcome several problems with this approach. For example, GRACE data are incorporated to better isolate the degree 1 related signals and ocean bottom pressure (OBP) model predictions are used as pseudo observations to improve the data coverage (e.g., Kusche and Schrama 2005; Wu et al. 2006). Swenson et al. (2008) proposed to estimate degree 1 coefficients by combing GRACE data with an OBP model. Such a method has been further developed by Sun et al. (2016a) to also estimate $J_{2}$ coefficients. The resulting $J_{2}$ solution is well compared to the SLR solutions, which are currently the most accurate source for $J_{2}$ (Meyrath et al. 2017). Sun et al. (2016b) further verified and refined the estimates by implementing a simulation study and optimizing the parameter settings. The geocenter motion estimates are proved to be accurate in terms of estimating surface mass changes when companioned with GRACE data (Sun et al. 2017). Hereafter, such a method is called the GRACE-OBP approach.

Finally, geocenter motion can be reconstructed with geophysical models. Many researchers have compared observed geocenter motion time series with their reconstructed solutions based on modeled mass variations of atmosphere, oceans, terrestrial water, glaciers and ice sheets, etc. (e.g., Dong et al. 1997; Chen et al. 1999; Dong et al. 2014; Collilieux et al. 2010). However, all the former efforts compared modeled geocenter motion with those based on solutions from the direct method, such as SLR and DORIS. The geocenter motion time series is poorly compared due to both systematic errors in the observations and deficiencies in the less constrained geophysical models. In this study, we reconstructed a new geocenter motion time series based on available state-of-the-art geophysical models and compared it with the GRACE-OBP solution. By doing so, we obtain in-depth knowledge of the geophysical interpretation of geocenter motion. According to Sun et al. (2016b), the linear trends in geocenter motion time series from the GRACE-OBP method are largely dependent on the applied GIA model, which still carry large uncertainties. Therefore, the comparison is focused on the seasonal geocenter motion arising from the presentday mass transport (PDMT). Linear trends in the geocenter motion time series originate from the solid Earth, and the mass loading is not considered at the time being.

\section{Geocenter motion time series from the GRACE-OBP method}

We have implemented the GRACE-OBP approach using the implementation parameters suggested by Sun et al. (2016b) in order to optimize the estimates of the seasonal variations in the resulting geocenter motion time series. In that study, the authors identified those parameters with an end-to-end simulation. That is, self-attraction and loading (SAL) effects are activated when distributing ocean waters; a buffer zone of $200 \mathrm{~km}$ wide is used to avoid signal leakage from continent to oceans due to the coarse spatial resolution of the GRACE data; the input GRACE solutions are truncated at degree 45 . These parameter settings are applicable for all GRACE solutions.

The GRACE-OBP method requires two data sets including the GRACE data and the degree 1 component of an OBP model. The input GRACE data are in the form of Stoke coefficients directly taken from the level-2 product (known as GSM). To obtain those GSM coefficients, highfrequency atmospheric and dynamic ocean effects are modeled and subtracted from raw GRACE data at early stages using the Atmosphere and Ocean Dealiasing level1B (AOD1B) product (Flechtner and Dobslaw 2013). Therefore, GSM coefficients should contain no atmospheric and dynamic ocean $(\mathrm{AO})$ effects provided that the AOD1B product is perfect. Monthly averages of AOD1B coefficients are stored in the GAC files. The projection of GAC on the oceans is an OBP model and stored in the GAD files. According to Swenson et al. (2008), when working with GSM coefficients, the degree 1 coefficients of the GAD need to be removed from the input degree 1 coefficients of the applied OBP model for consistency. Therefore, if we apply the OBP model extracted from the AOD1B product as the input of the GRACE-OBP method, the input OBP degree 1 coefficients becomes zeros. At the same time, the obtained geocenter motion contains no AO effects, and need to add back the GAC degree 1 coefficients to obtain the full geocenter motion.

In this study, we obtain geocenter motion time series based on the latest GRACE solutions from three official centers, namely, the Center for Space Research (CSR) RL05 solution (Bettadpur 2012), the Geo Forschungs Zentrum (GFZ) RL05a solution (Dahle et al. 2013), and the Jet Propulsion Laboratory (JPL) RL05 solution (Watkins 2012) (see Fig. 1). All three solutions are using the same AOD1B product, and the input OBP degree 1 coefficients are also the same. Therefore, the resulting geocenter motion time series are somewhat correlated. The 
Fig. 1 Geocenter motion time series estimated from the GRACE-OBP approach. The gray, blue, and red time series are results based on GFZ RL05, JPL RL05, and CSR RL05 GRACE solutions, respectively. The linear trends are removed from all time series, which implies that the GIA signals are not included. The AO effects predicted by the dealiasing product AOD1B are not restored

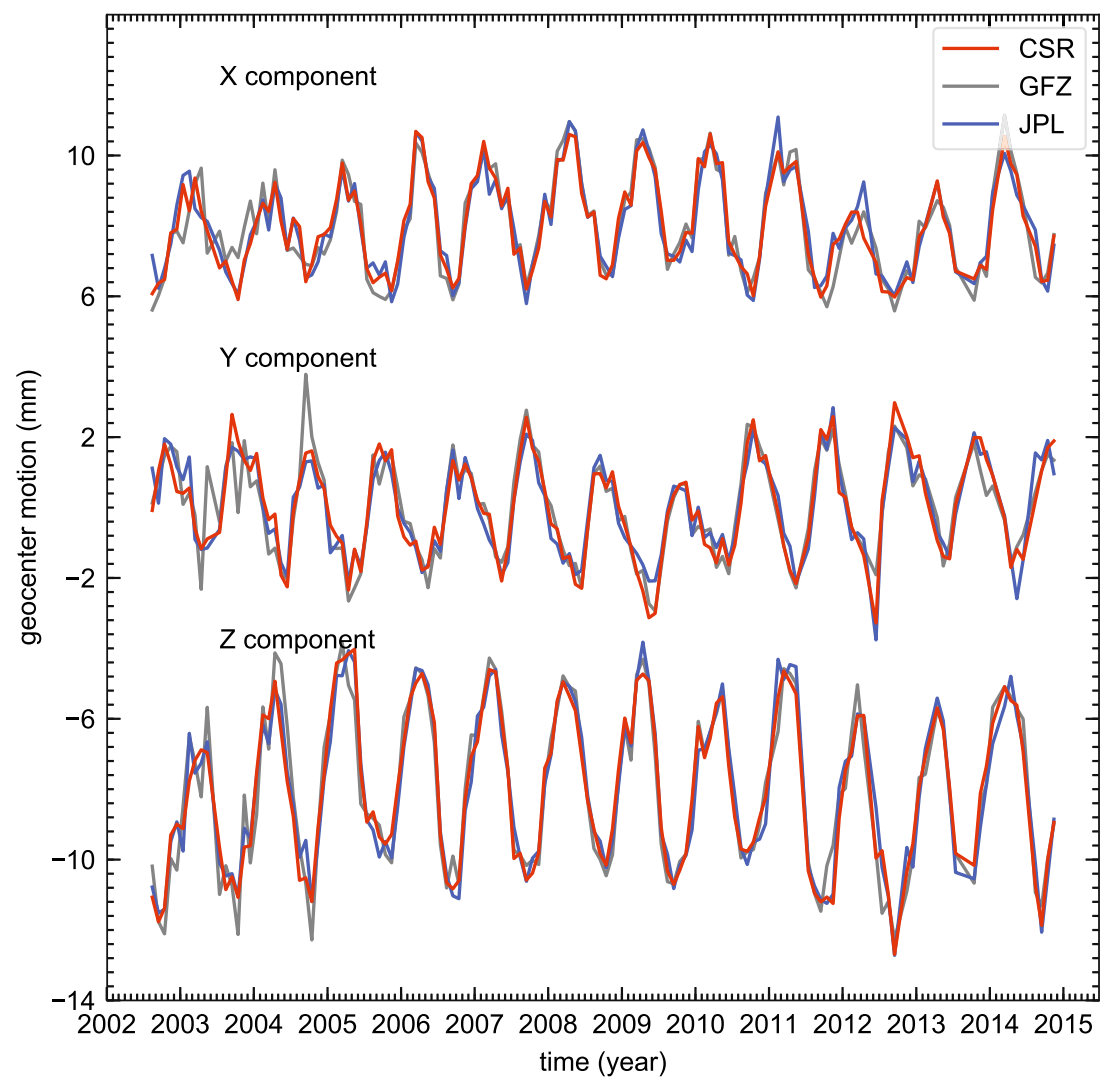

good comparison of the results, however, show that the geocenter motion estimates are not sensitive to the choice of GRACE solutions. We believe that the average of the three geocener motion time series should be sufficiently representative.

It is now clear that the AO mass variations are the monthly averages derived from the AOD1B product. The AOD1B product is based on the European Center for
Medium-Range Weather Forecasts (ECMWF) (Dee et al. 2011) and the Ocean Model for Circulation and Tides (OMCT) (Thomas 2002), which is driven by the ECMWF. The contributions of the AO mass variations are shown in Fig. 2. As mentioned above, the total geocenter motion time series can be found by restoring these contributions to the GRACE-OBP solution. The AO mass variations contribute significantly to the climate-driven seasonal
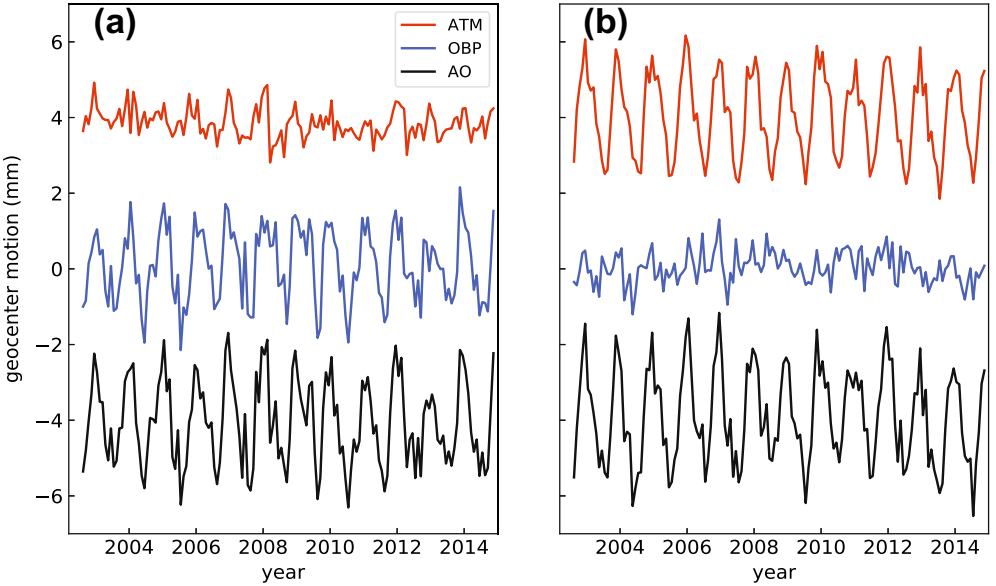

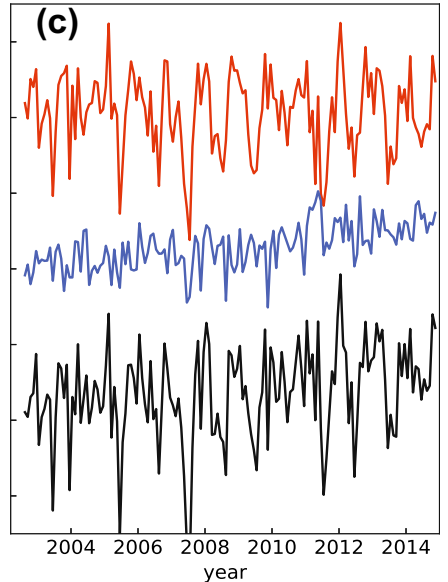

Fig. 2 Geocenter motion due to AO. a-c $X, Y$, and $Z$ geocenter motion components, respectively. OBP denotes the ocean bottom pressure, which is based on the GAD product. Note that the atmospheric contribution over oceans is also included due to the inverted barometer effect. ATM represents the GAC-GAD and represent the contribution of continental atmosphere. $\mathrm{AO}$ is the combination of OBP and ATM 
geocenter motion. The GRACE-OBP approach assumes that the AO-induced geocenter motion is known and accurate. This, however, is not necessarily true. Sun et al. (2016b) implemented the GRACE-OBP method while using an alternative OBP model, i.e., the estimating the circulation and climate of the ocean (ECCO) (Fukumori 2002; Kim et al. 2007). They found that the annual amplitudes of degree 1 coefficients are different within $15 \%$. For annual phase estimates, the largest differences are 11 days. The differences caused using two OBP models are not significant, but still need to be further analyzed in future studies. This, however, is not the primary purpose of this study.

\section{Geocenter motion predicted by geophysical models}

It is well known that seasonal geocenter motion is primarily driven by surface mass loading, which can be attributed to multiple sources. The AO effects have already been given in "Geocenter motion time series from the GRACE-OBP method". Here, we consider the contributions of mass variations over both Antarctica and Greenland ice sheets, continental glaciers, terrestrial water storage, as well as total ocean mass changes. By summing up all these contributors, one should be able to reconstruct the GRACE-OBP-based geocenter motion solution.

We first obtain mass loading fields represented in terms of equivalent water height from geophysical models on a monthly basis. Then, the degree 1 mass coefficients are estimated by performing spherical harmonic analysis and converted to geocenter motion estimates. In the following, we give a brief introduction of the geophysical models used.

\section{Ice sheets and continental glaciers}

Mass changes over ice sheets as well as continental glaciers can be obtained from several methodologies. It can be estimated using GRACE gravimetry measurements (Jacob et al. 2012), altimetry measurements (Zwally et al. 2005) and the input-output method (Rignot et al. 2008). However, solutions from all techniques have reconciled estimates of ice-sheet mass balance recently (Shepherd et al. 2012).

Here, for both Antarctica and Greenland ice sheets, we use the input-output method to estimate their mass variations following Frederikse et al. (2016). The input comes from the Regional Atmospheric Climate Model (RACMO) 2.3 (van de Berg and Medley 2016; Noël et al. 2015; Wessem et al. 2014) surface mass balance (SMB), while the output is the ice discharge acceleration which can be taken from van den Broeke et al. (2016) for Greenland (6.6 $\mathrm{Gt} \mathrm{year}^{-1}$ ) and Rignot et al. (2011) for Antarctica (9.0 Gt year $^{-1}$ ). The contribution of ice sheets is further validated by the estimates from the Ice-sheet Mass Balance Intercomparison Exercise (IMBIE) project and GRACE data. The Antarctica and Greenland ice-sheet mass variations are denoted as ANT and GRE hereafter.

For continental glaciers mass balance (GLA), we use the estimates based on Marzeion et al. (2015). So far, only annual observations in the glacier mass balance are available. Although monthly data are obtained based on linear interpolation, it hardly contributes to any seasonal changes of the geocenter motion. However, we still decided to include it for completeness.

\section{Terrestrial water storage}

Terrestrial water storage (TWS) includes the contribution from soil moisture, snow, surface water, and groundwater, etc. It is critical in the global hydrology system. Due to the lack of global-scale data constraints, the TWS is currently modeled with data assimilation techniques. As a result, the large-scale mass redistribution derived from a TWS model may not be accurate. Here, we choose the Global land data assimilation system (GLDAS) products, which currently contains only the snow, soil moisture, and canopy water. The groundwater as well as separate surface water components such as rivers and lakes, on the other hand, are not included. GLDAS has four different models including Noah model (NOAH), the community land model (CLM), the Mosaic model (MOS), and the variable infiltration capacity model (VIC) (Rodell et al. 2004). We integrated the snow, canopy water, and all soil moisture layers for each of the four models to obtain the total water content. The uncertainties of these models are not available and we expect using the average of them allows for the removal of some random noises in the geocenter motion time series. However, the CLM model failed to predict the seasonal variabilities in the geocenter motion time series (see Fig. 3). Therefore, we take the average of NOAH, VIC, and MOS models as the final solution of the GLDAS model.

Another commonly used model, the WaterGAP Global Hydrology Model (WGHM), is also used for the purpose of mutual comparisons. In this study, the WGHM TWS is kindly provided by Müller Schmied (personal communication) based on the latest WaterGAP $2.2 \mathrm{c}$ model (Müller Schmied et al. 2014, 2016). Different from the GLDAS model, the WGHM model also computes the variations in groundwater storage.

It is also worth noting that Greenland and its periphery area $(300 \mathrm{~km})$ are masked out from both models as snow, and ice dynamics are poorly modeled there. 

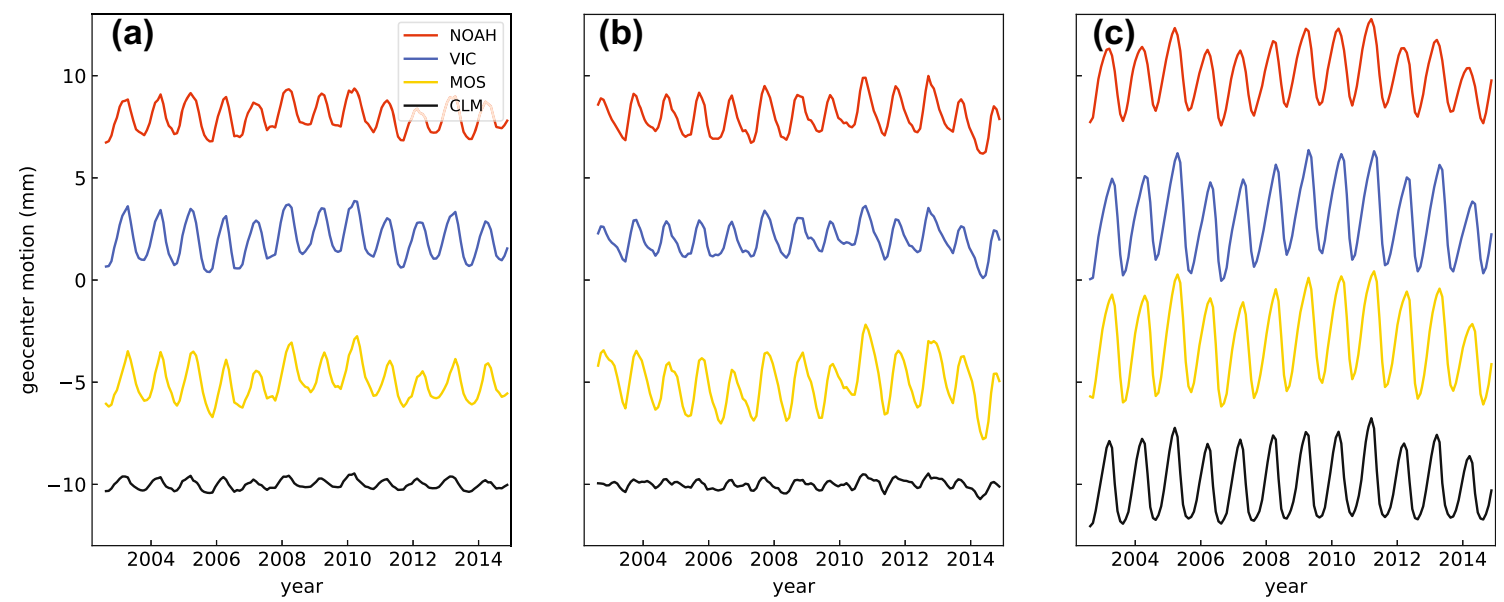

Fig. 3 Geocenter motion due to GLDAS NOAH, VIC, MOS, and CLM models

\section{Self-attraction and loading effects}

The geophysical models adopted in this study are not coupled meaning that the sum of all these models does not ensure the mass conservation of the entire Earth system. This problem was usually ignored in former efforts and is recently solved by applying the so-called Greatbatch correction. This correction simply adds/removes a thin uniform layer of water from oceans to balance the mass variations from all other components combined (e.g., Swenson et al. 2008; Dong et al. 2014). However, such a uniform distribution is not realistic as it ignores the impact of SAL effects. Regional mass redistributes modify the Earth's gravity field and ocean waters will passively redistribute to align with the newly formed equipotential surface. The water flows in to or out from the ocean basins will not be distributed over oceans as a uniform layer but following certain patterns known as fingerprints (e.g., Tamisiea et al. 2010), which can be computed through the sea-level equation (e.g., Farrell and Clark 1976; Mitrovica et al. 2001). Therefore, we take into account these effects to obtain more realistic geocenter motion estimates due to total ocean mass variations $(\mathrm{OCN})$.

\section{Results}

In Fig. 4, we show the five considered contributing sources of geocenter motion excluding the AO component. The most important contributing source of the seasonal signals in geocenter motion is the TWS and the OCN. As discussed above, the OCN needs to balance out the sum of mass changes from all other components to ensure the total mass conservation in the Earth system, the OCN-induced geocenter motion is thus strongly correlated with the combination of other contributing sources. we show the geocenter motion time series derived from GLDAS and WGHM models (see Fig. 5). Both solutions are featured with clear and similar seasonal variations. Switching only the hydrology models used for the TWS component while keeping all other geophysical models unchanged will also change the $\mathrm{OCN}$-induced geocenter motion accordingly (see Fig. 6).

In Fig. 7, we show the reconstructed geocenter motion time series by combining all the components shown in Fig. 4. On top of the reconstructed time series, the GRACE-OBP solution is also shown as the reference. We further estimate the amplitude and phase of the annual variations of the geocenter motion to facilitate a more detailed comparison between the reconstructed and observed solutions (see Table 1). In Table 2, we calculate the variance of the observed geocenter motion explained by individual components of the considered contributing sources. The explained variance $(R)$ is defined as $R=1-\operatorname{var}<$ obs - rec $>/$ var $<$ obs $>$, where obs represent the GRACE-OBP solution after restoring the GAC product (the AO effects), rec denotes the reconstructed solution).

In the upper row of Fig. 7, we show the reconstructed geocenter motion solutions with (Panel a) and without (Panel b) adding back the AO effects. The TWS component is estimated from the GLDAS model. In the lower row, the only difference from the upper ones is that the TWS component is modeled using the WGHM model. Without considering the AO effects, the observed GSM-like geocenter motion time series are well recovered by the selected geophysical contributions in the $X$ and $Z$ directions (Panels a, c), with the reconstructed solution explaining about $80 \%$ of the variance in the observed one (see Table 2). All the main features in the observed geocenter motion time series are well explained. The annual amplitude and phase are also relatively close. The mean annual 

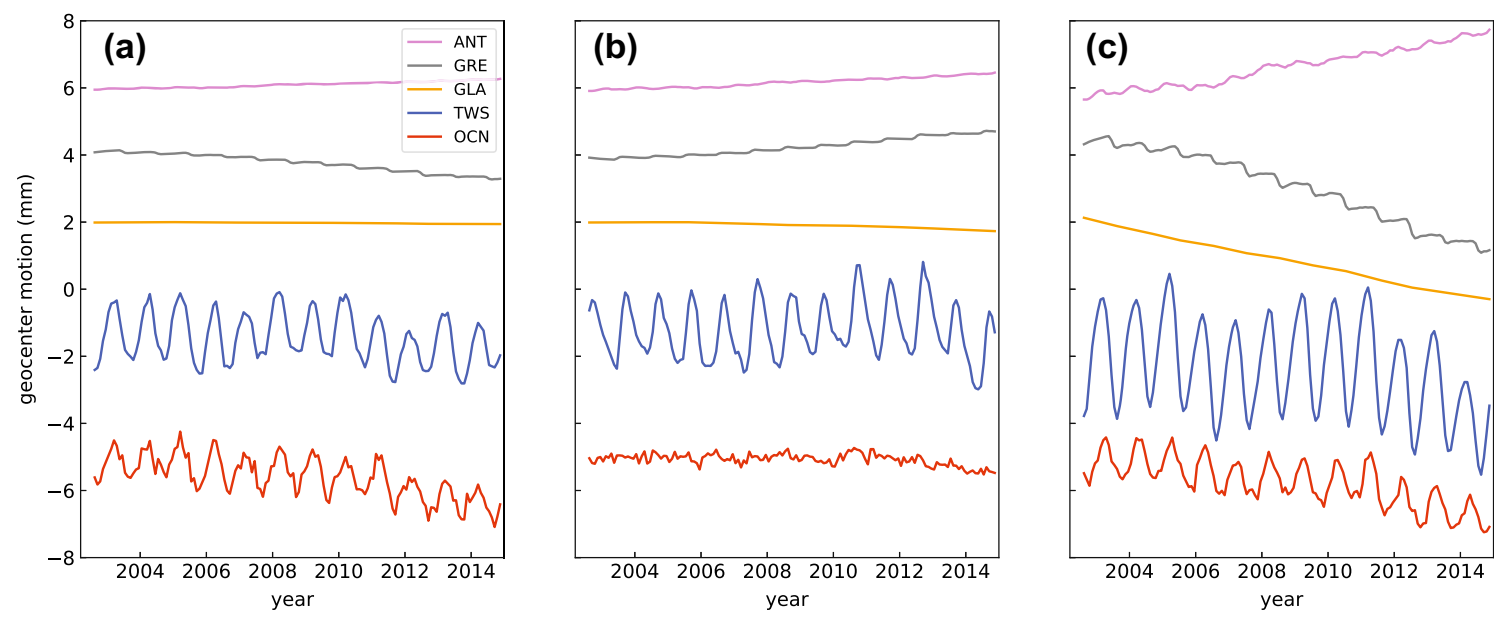

Fig. 4 Contributing sources of the GSM-like geocenter motion. GSM-like means that the AO component is not included
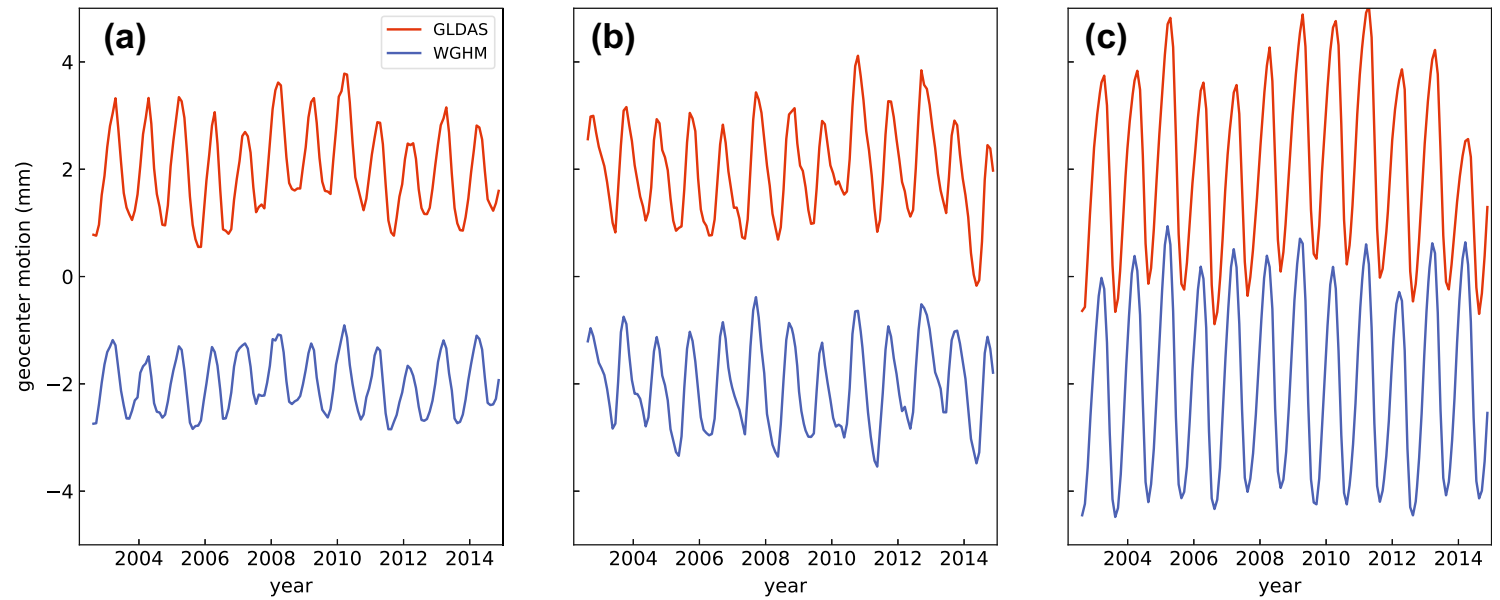

Fig. 5 Geocenter motion due to GLDAS and WGHM models
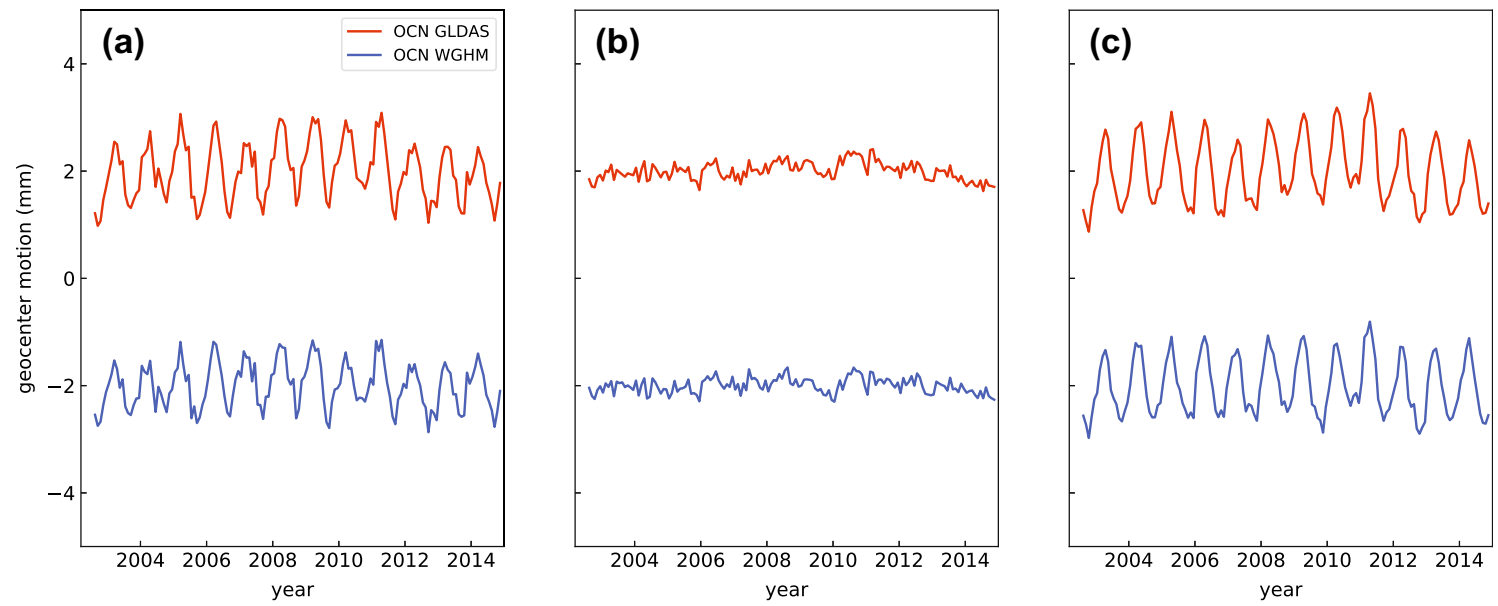

Fig. 6 Geocenter motion due to OCN component

amplitudes of the two reconstructed solutions are 1.47 and $3.04 \mathrm{~mm}$, respectively, for the $X$ and $Z$ component, which are quite close to those from the observed solution (1.56 and $2.82 \mathrm{~mm}$ ). The annual phases of either of the two reconstructed solutions are also close to the observed solution (within 2 weeks). Unfortunately, the agreement is 

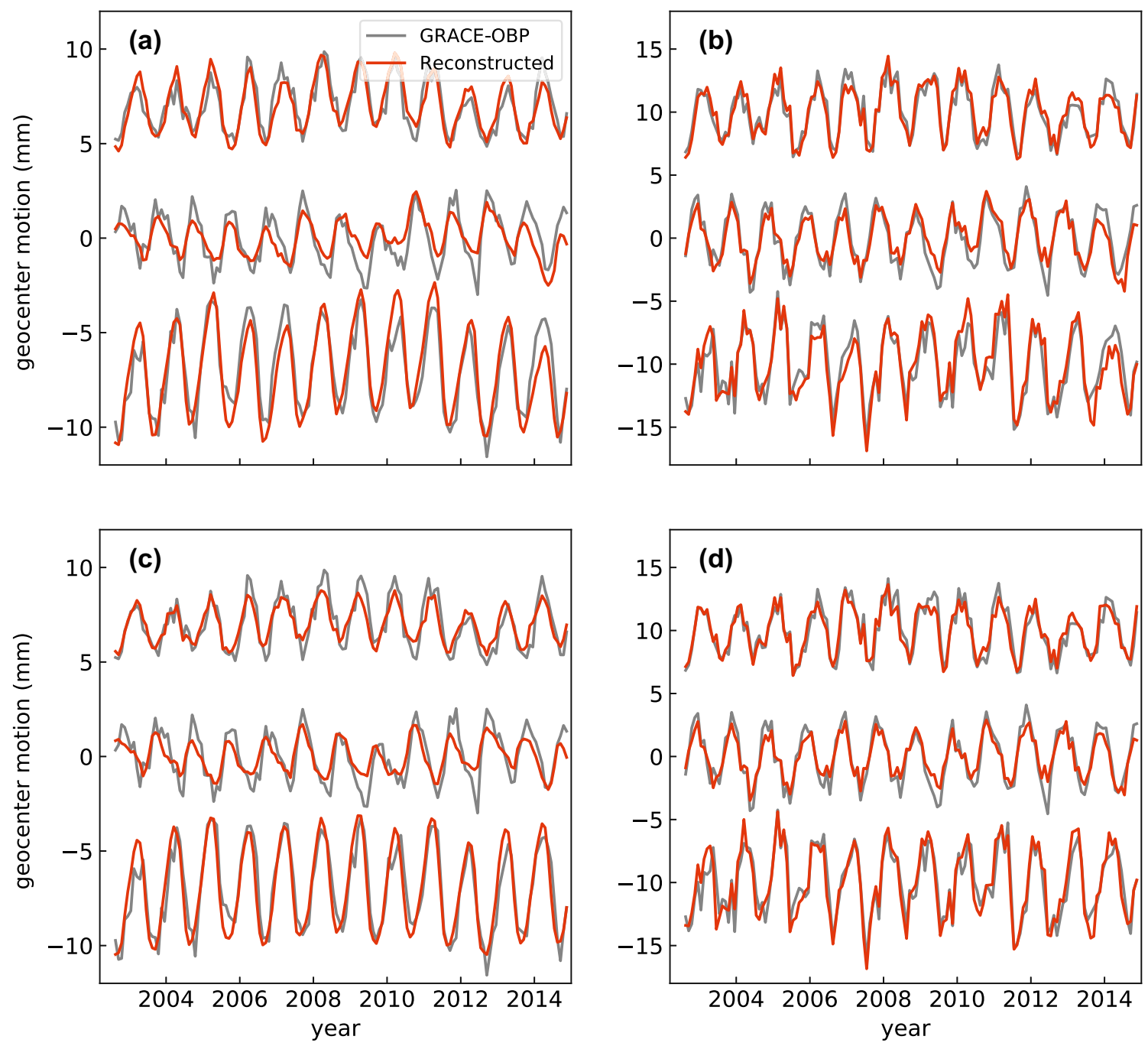

Fig. 7 Comparison between the reconstructed and the estimated geocenter motion time series. Geocenter components $X, Y$ and $Z$ are shown in the top, middle, and bottom of the panels. a, c The GSMlike time series which do not include the AO effects. b, d The total geocenter motion time series, which are the GSM-like geocenter

motion time series plus the AO effects. The only difference between the upper panels and lower panels is the TWS component used to obtain the reconstructed solutions. The GLDAS model is used for the plots in the upper panels, while the WGHM model is used in the lower ones

Table 1 Annual variations of the reconstructed and GRACE-OBP-based geocenter motion time series

\begin{tabular}{|c|c|c|c|c|c|c|}
\hline & \multicolumn{2}{|l|}{$X\left(C_{11}\right)$} & \multicolumn{2}{|l|}{$Y\left(S_{11}\right)$} & \multicolumn{2}{|l|}{$Z\left(C_{10}\right)$} \\
\hline & Amp (mm) & Pha (day) & Amp (mm) & Pha (day) & Amp (mm) & Pha (day) \\
\hline GRACE-OBP & $1.56 \pm 0.08$ & $86 \pm 3$ & $1.60 \pm 0.07$ & $301 \pm 3$ & $2.82 \pm 0.09$ & $86 \pm 2$ \\
\hline Reconstructed GLDAS & $1.72 \pm 0.06$ & $83 \pm 2$ & $1.00 \pm 0.05$ & $294 \pm 4$ & $2.96 \pm 0.08$ & $81 \pm 2$ \\
\hline Reconstructed WGHM & $1.22 \pm 0.04$ & $72 \pm 2$ & $0.98 \pm 0.05$ & $279 \pm 3$ & $3.12 \pm 0.05$ & $72 \pm 1$ \\
\hline TOT GRACE-OBP & $2.28 \pm 0.13$ & $52 \pm 3$ & $2.79 \pm 0.09$ & $327 \pm 2$ & $2.92 \pm 0.18$ & $69 \pm 3$ \\
\hline TOT reconstructed GLDAS & $2.47 \pm 0.10$ & $51 \pm 2$ & $2.22 \pm 0.09$ & $331 \pm 2$ & $3.12 \pm 0.16$ & $65 \pm 3$ \\
\hline TOT reconstructed WGHM & $2.19 \pm 0.10$ & $39 \pm 3$ & $2.04 \pm 0.07$ & $327 \pm 2$ & $3.41 \pm 0.14$ & $57 \pm 2$ \\
\hline
\end{tabular}

Note that the uncertainties shown are formal errors, which are estimated from the post-fit residuals and do not reflect the real uncertainty of the estimates 
Table 2 Variance of the observed geocenter motion explained by the reconstructed solutions and contributing sources

\begin{tabular}{|c|c|c|c|c|c|c|}
\hline & \multicolumn{3}{|c|}{ GLDAS } & \multicolumn{3}{|c|}{ WGHM } \\
\hline & $X(\%)$ & $Y(\%)$ & $Z(\%)$ & $X(\%)$ & $Y(\%)$ & $Z(\%)$ \\
\hline GSM & 78 & 61 & 80 & 79 & 67 & 85 \\
\hline TOT & 90 & 85 & 85 & 90 & 88 & 88 \\
\hline $\mathrm{AO}$ & 54 & 62 & 25 & - & - & - \\
\hline ANT & 1 & 0 & 3 & - & - & - \\
\hline GRE & 2 & 1 & 7 & - & - & - \\
\hline GLA & 0 & 0 & 0 & - & - & - \\
\hline TWS & 42 & 42 & 39 & 36 & 33 & 67 \\
\hline OCN & 36 & -4 & 29 & 32 & -2 & 29 \\
\hline
\end{tabular}

less well in the $Y$ direction as only about $60 \%$ of the variance has been explained. This is also reflected in the annual amplitude estimate $(1.6 \mathrm{~mm}$ for the observed solution and only about $1 \mathrm{~mm}$ for the reconstructed solutions). Since the seasonal variations mainly come from the TWS component in this direction, the discrepancies can be largely attributed to the model deficiencies in both GLDAS and WGHM models. After restoring the AO effects (Panel $\mathrm{b}, \mathrm{d})$, we notice that the full geocenter motion time series variance can be explained by over $85 \%$ using either of the two hydrology models. The annual amplitudes and phases are in line with solutions based on other techniques and thus can be considered as reasonable.

In view of the good agreement of the reconstructed geocenter motions and the observed solution, it is possible for us to quantify the contribution of each component in the Earth system to the total geocenter motion. We show this result also in terms of explained variance (see Table 2), but based on a slightly different definition, i.e., $R=1-\operatorname{var}<$ obs - com $>/ \operatorname{var}<$ obs $>$, with com the individual contributing sources. The melting of the continental glaciers and the polar ice sheets dominate the linear trend estimates in the geocenter motion time series (see Fig. 4). They, however, have only minor contributions to the seasonal signals in the geocenter motion time series. Glaciers contribute negligibly to all three components as expected. Ice sheets have a slightly larger contribution in the $Z$ direction, but still explain less than $10 \%$ of the observed variance.

Atmosphere and dynamic ocean is the largest contributing source for seasonal geocenter motion in both $X$ and $Y$ components. When combined, they explain 54 and $62 \%$ of the variance in those two directions, respectively. In the $Z$ direction, it accounts for $25 \%$ of the variance. TWS is another major contributing source. Based on the GLDAS model, it explains about $40 \%$ of the observed variances in the $X, Y$, and $Z$ directions. However, the
$Z$ geocenter motion is much better explained when using the WGHM model (67\%). This is probably because the WGHM model also models the groundwater component. Finally, ocean mass variations due to ocean-land mass exchanges also play a critical role in recovering the observed $X$ and $Z$ geocenter time series. Such a contribution is responsible for about $30 \%$ of the observed $X$ and $Z$ component variances, respectively. The minor impact on the $Y$ component is expected, since the $Y$ component of geocenter motion is mostly influenced by continental mass changes rather than oceanic ones (Chen et al. 1999).

\section{Conclusions and discussion}

In this study, we use geophysical models to reproduce the seasonal geocenter motion time series estimated from the GRACE-OBP approach. For the time being, AO effects modeled by the GAC products are assumed to be accurate. Under this assumption, we conclude that the AO and TWS components and the associating ocean responses are the main contributors to the seasonal variations in geocenter motion. They combined explain almost the entire seasonal variations in geocenter motion time series. The contribution from ANT and GRE, on the other hand, is rather limited. Currently, we are still not able to accurately determine the contribution of continental glaciers due to the low temporal resolution of the observations.

The geocenter motion in the $Y$ direction, unlike those in the other two directions, is not that well explained by the selected geophysical models. This is probably due to the lack or mis-modeling of groundwater component in the GLDAS and WGHM models. Note that WGHM claims to contain the groundwater component and works indeed better than that of the GLDAS model. This becomes evident as the reconstructed geocenter motion involving the WGHM model explains the observed solution slightly better. However, the groundwater component, at least its low-frequency components, are not accurate enough, since the large discrepancy between the reconstructed and observed $Y$ direction geocenter motion time series is still exists. Such groundwater component significantly affects the estimation of the geocenter motion in the $Y$ direction, whereas it has only secondary effects on the other two directions. This is expected, since the groundwater is trapped over land areas and may only affect the OCN component through the SAL effects, which are likely to be minor. Anthropological impacts, such as groundwater depletion and building dams, could also have some effects on the geocenter motion, but likely restricted to the linear trend estimates. To a lesser extent, the discrepancies may also relate to the omission of the seasonal variabilities in the GLA component. Mass variations in the GLA 
component will directly affect the total ocean mass changes and thus affects the geocenter motion in all three directions. The good agreement in the $X$ and $Z$ of the reconstructed and the observed geocenter motion time series indicates the GLA has a rather limited contribution to the seasonal signals in the geocenter motion time series.

The modeled AO effects are used in both the GRACEOBP solution and the reconstructed solution. Therefore, this study is not able to conclude if the observed AOinduced geocenter motion and the remodel-predicted solution are reconciled or not. To do so, a geocenter motion solution independent from any geophysical models is better suited for such a comparison study. We recently noted that $\mathrm{Wu}$ et al. (2017) provided a geocenter motion time series largely based on real data which may be used in future investigations.

In this study, we exclude the solid Earth contributions to geocenter motions by removing the trend in the time series. The side effect of doing so is that we also remove the trend due to the surface mass transport. Since GIA models are very uncertain, it is premature to discuss the geocener motion trend using the GRACE-OBP approach. However, there are already approaches that allow us to obtain promising geocenter motion trend (e.g., Wu et al. 2010; Rietbroek et al. 2012, 2016), which may be suited to study the contributing sources of geocenter motion trend in the next step.

\section{References}

Bettadpur S (2012) UTCSR Level-2 Processing Standards Document. Technical Version 4, Univ. Texas, Austin

Blewitt G (2003) Self-consistency in reference frames, geocenter definition, and surface loading of the solid Earth. J Geophys Res Solid Earth 108(B2):2103. https://doi.org/10.1029/ 2002JB002082

Blewitt G, Lavallée D, Clarke P, Nurutdinov K (2001) A new global mode of Earth deformation: seasonal cycle detected. Science (New York, NY) 294(5550):2342-2345. https://doi.org/10.1126/ science. 1065328

van den Broeke M, Enderlin E, Howat I, Kuipers Munneke P, Noël B, van de Berg WJ, van Meijgaard E, Wouters B (2016) On the recent contribution of the Greenland ice sheet to sea level change. Cryosphere Discuss 2016:1-26. https://doi.org/10.5194/ tc-2016-123

Chen JL, Wilson CR, Eanes RJ, Nerem RS (1999) Geophysical interpretation of observed geocenter variations. J Geophys Res Solid Earth 104(B2):2683-2690. https://doi.org/10.1029/ 1998JB900019

Cheng MK, Ries JC, Tapley BD (2013) Geocenter variations from analysis of SLR data. In: Altamimi Z, Collilieux X (eds) Reference frames for applications in geosciences, no. 138 in International Association of Geodesy Symposia, Springer, Berlin, pp 19-25

Collilieux X, Altamimi Z, Coulot D, van Dam T, Ray J (2010) Impact of loading effects on determination of the International
Terrestrial Reference Frame. Adv Space Re 45(1):144-154. https://doi.org/10.1016/j.asr.2009.08.024

Dahle C, Flechtner F, Gruber C, König D, König R, Michalak G, Neumayer KH, GFZ DG (2013) GFZ GRACE level-2 processing standards document for level-2 product release 0005. Deutsches GeoForschungsZentrum GFZ

Dee DP, Uppala SM, Simmons AJ, Berrisford P, Poli P, Kobayashi S, Andrae U, Balmaseda MA, Balsamo G, Bauer P, Bechtold P, Beljaars ACM, van de Berg L, Bidlot J, Bormann N, Delsol C, Dragani R, Fuentes M, Geer AJ, Haimberger L, Healy SB, Hersbach H, Hólm EV, Isaksen L, Kållberg P, Köhler M, Matricardi M, McNally AP, Monge-Sanz BM, Morcrette JJ, Park BK, Peubey C, de Rosnay P, Tavolato C, Thépaut JN, Vitart F (2011) The ERA-interim reanalysis: configuration and performance of the data assimilation system. Q J R Meteorol Soc 137(656):553-597. https://doi.org/10.1002/qj.828

Dong D, Dickey JO, Chao Y, Cheng MK (1997) Geocenter variations caused by atmosphere, ocean and surface ground water. Geophys Res Lett 24(15):1867-1870. https://doi.org/10.1029/97GL01849

Dong D, Qu W, Fang P, Peng D (2014) Non-linearity of geocentre motion and its impact on the origin of the terrestrial reference frame. Geophys J Int 198(2):1071-1080. https://doi.org/10.1093/ gji/ggu 187

Farrell WE, Clark JA (1976) On postglacial sea level. Geophys J R Astron Soc 46(3):647-667. https://doi.org/10.1111/j.1365-246X. 1976.tb01252.x

Feissel-Vernier M, Bail KL, Berio P, Coulot D, Ramillien G, Valette JJ (2006) Geocentre motion measured with DORIS and SLR, and predicted by geophysical models. J Geod 80(8-11):637-648. https://doi.org/10.1007/s00190-006-0079-z

Flechtner F, Dobslaw H (2013) AOD1b Product Description Document for Product Release. 05. GFZ German Research Centre for Geosciences

Frederikse T, Riva R, Kleinherenbrink M, Wada Y, van den Broeke M, Marzeion B (2016) Closing the sea level budget on a regional scale: trends and variability on the Northwestern European continental shelf. Geophys Res Lett 43(20):10864-10872. https://doi.org/10.1002/2016GL070750

Fukumori I (2002) A Partitioned Kalman filter and smoother. Mon Weather Rev 130(5):1370-1383. https://doi.org/10.1175/15200493(2002) $130<1370:$ APKFAS $>2.0$. CO; 2

Jacob T, Wahr J, Pfeffer WT, Swenson S (2012) Recent contributions of glaciers and ice caps to sea level rise. Nature 482(7386):514-518. https://doi.org/10.1038/nature 10847

Kim SB, Lee T, Fukumori I (2007) Mechanisms controlling the interannual variation of mixed layer temperature averaged over the Niño-3 region. J Clim 20(15):3822-3843. https://doi.org/10. 1175/JCLI4206.1

Kusche J, Schrama EJO (2005) Surface mass redistribution inversion from global GPS deformation and gravity recovery and climate experiment (GRACE) gravity data. J Geophys Res Solid Earth 110(B9). https://doi.org/10.1029/2004JB003556

Marzeion B, Leclercq PW, Cogley JG, Jarosch AH (2015) Brief communication: global reconstructions of glacier mass change during the 20th century are consistent. Cryosphere 9(6):2399-2404. https://doi.org/10.5194/tc-9-2399-2015

Meindl M, Beutler G, Thaller D, Dach R, Jäggi A (2013) Geocenter coordinates estimated from GNSS data as viewed by perturbation theory. Adv Space Res 51(7):1047-1064. https://doi.org/10. 1016/j.asr.2012.10.026

Meyrath T, Rebischung P, van Dam T (2017) GRACE era variability in the Earth's oblateness: a comparison of estimates from six different sources. Geophys J Int 208(2):1126-1138. https://doi. org/10.1093/gji/ggw441

Mitrovica JX, Tamisiea ME, Davis JL, Milne GA (2001) Recent mass balance of polar ice sheets inferred from patterns of global sea- 
level change. Nature 409(6823):1026-1029. https://doi.org/10. $1038 / 35059054$

Müller Schmied H, Eisner S, Franz D, Wattenbach M, Portmann FT, Flörke M, Döll P (2014) Sensitivity of simulated global-scale freshwater fluxes and storages to input data, hydrological model structure, human water use and calibration. Hydrol Earth Syst Sci 18(9):3511-3538

Müller Schmied H, Adam L, Eisner S, Fink G, Flörke M, Kim H, Oki T, Portmann FT, Reinecke R, Riedel C et al (2016) Variations of global and continental water balance components as impacted by climate forcing uncertainty and human water use. Hydrol Earth Syst Sci 20(7):2877-2898

Noël B, van de Berg WJ, van Meijgaard E, Kuipers Munneke P, van de Wal RSW, van den Broeke MR (2015) Evaluation of the updated regional climate model RACMO2.3: summer snowfall impact on the Greenland Ice Sheet. Cryosphere 9(5):1831-1844. https://doi.org/10.5194/tc-9-1831-2015.

Petit G, Luzum B (2010) IERS conventions (2010) Technical Note 36. Verlag des Bundesamts für Kartographie und Geodäsie, Frankfurt am Main

Ray J (1999) IERS Analysis Campaign to Investigate Motions of the Geocenter. Technical Note 25, Central Bureau of IERS Observatioire de Paris, Paris

Rietbroek R, Fritsche M, Brunnabend SE, Daras I, Kusche J, Schröter J, Flechtner F, Dietrich R (2012) Global surface mass from a new combination of GRACE, modelled OBP and reprocessed GPS data. J Geodyn 59-60:64-71. https://doi.org/10.1016/j.jog. 2011.02.003

Rietbroek R, Brunnabend SE, Kusche J, Schröter J, Dahle C (2016) Revisiting the contemporary sea-level budget on global and regional scales. Proc Natl Acad Sci 113(6):1504-1509. https:// doi.org/10.1073/pnas.1519132113

Rignot E, Box JE, Burgess E, Hanna E (2008) Mass balance of the Greenland ice sheet from 1958 to 2007. Geophys Res Lett 35(20):L20,502. https://doi.org/10.1029/2008GL035417

Rignot E, Velicogna I, van den Broeke MR, Monaghan A, Lenaerts JTM (2011) Acceleration of the contribution of the Greenland and Antarctic ice sheets to sea level rise. Geophys Res Lett 38(5):L05,503. https://doi.org/10.1029/2011GL046583

Rodell M, Houser PR, Jambor U, Gottschalck J, Mitchell K, Meng CJ, Arsenault K, Cosgrove B, Radakovich J, Bosilovich M, Entin* JK, Walker JP, Lohmann D, Toll D (2004) The global land data assimilation system. Bull Am Meteorol Soc 85(3):381-394. https://doi.org/10.1175/BAMS-85-3-381

Shepherd A, Ivins ER, AG, Barletta VR, Bentley MJ, Bettadpur S, Briggs KH, Bromwich DH, Forsberg R, Galin N, Horwath M, Jacobs S, Joughin I, King MA, Lenaerts JTM, Li J, Ligtenberg SRM, Luckman A, Luthcke SB, McMillan M, Meister R, Milne G, Mouginot J, Muir A, Nicolas JP, Paden J, Payne AJ, Pritchard H, Rignot E, Rott H, Sørensen LS, Scambos TA, Scheuchl B, Schrama EJO, Smith B, Sundal AV, Angelen JHv, Berg WJvd, Broeke MRvd, Vaughan DG, Velicogna I, Wahr J, Whitehouse PL, Wingham DJ, Yi D, Young D, Zwally HJ (2012) A reconciled estimate of ice-sheet mass balance. Science 338(6111):1183-1189. https://doi.org/10.1126/science.1228102

Sun Y, Ditmar P, Riva R (2016a) Observed changes in the Earth's dynamic oblateness from GRACE data and geophysical models. J Geod 90(1):81-89. https://doi.org/10.1007/s00190-015-0852-y

Sun Y, Riva R, Ditmar P (2016b) Optimizing estimates of annual variations and trends in geocenter motion and $\mathrm{J} 2$ from a combination of GRACE data and geophysical models. J Geophys Res Solid Earth 121(11):8352-8370. https://doi.org/10.1002/ 2016JB013073

Sun Y, Ditmar P, Riva R (2017) Statistically optimal estimation of degree-1 and C20 coefficients based on GRACE data and an ocean bottom pressure model. Geophys J Int. https://doi.org/10. 1093/gji/ggx241

Swenson S, Chambers D, Wahr J (2008) Estimating geocenter variations from a combination of GRACE and ocean model output. J Geophys Res Solid Earth 113(B8):B08,410. https://doi. org/10.1029/2007JB005338

Tamisiea ME, Hill EM, Ponte RM, Davis JL, Velicogna I, Vinogradova NT (2010) Impact of self-attraction and loading on the annual cycle in sea level. J Geophys Res Oceans 115(C7):C07,004. https://doi.org/10.1029/2009JC005687

Thomas M (2002) Ocean induced variations of Earth's rotation results from a simultaneous model of global circulation and tides. $\mathrm{PhD}$ thesis, Univ. of Hamburg, Germany

van de Berg WJ, Medley B (2016) Brief communication: upper-air relaxation in RACMO2 significantly improves modelled interannual surface mass balance variability in Antarctica. Cryosphere 10(1):459-463. https://doi.org/10.5194/tc-10-459-2016

Watkins M (2012) JPL Level-2 Processing Standards Document. Technical Version 4, Jet Propulsion Laboratory

Wessem JMV, Reijmer CH, Morlighem M, Mouginot J, Rignot E, Medley B, Joughin I, Wouters B, Depoorter MA, Bamber JL, Lenaerts JTM, Berg WJVD, Broeke MRVD, Meijgaard EV (2014) Improved representation of East Antarctic surface mass balance in a regional atmospheric climate model. J Glaciol 60(222):761-770. https://doi.org/10.3189/2014JoG14J051

Wu X, Heflin MB, Ivins ER, Argus DF, Webb FH (2003) Large-scale global surface mass variations inferred from GPS measurements of load-induced deformation. Geophys Res Lett 30(14). https:// doi.org/10.1029/2003GL017546

Wu X, Heflin MB, Ivins ER, Fukumori I (2006) Seasonal and interannual global surface mass variations from multisatellite geodetic data. J Geophys Res Solid Earth 111(B9). https://doi. org/10.1029/2005JB004100

Wu X, Heflin MB, Schotman H, Vermeersen BLA, Dong D, Gross RS, Ivins ER, Moore AW, Owen SE (2010) Simultaneous estimation of global present-day water transport and glacial isostatic adjustment. Nat Geosci 3(9):642-646. https://doi.org/ 10.1038 /ngeo938

Wu X, Kusche J, Landerer FW (2017) A new unified approach to determine geocentre motion using space geodetic and GRACE gravity data. Geophys J Int 209(3):1398-1402. https://doi.org/ $10.1093 / \mathrm{gji} / \mathrm{ggx} 086$

Zannat UJ, Tregoning P (2017a) Estimating network effect in geocenter motion: applications. J Geophys Res Solid Earth 122(10):2017JB014,247. https://doi.org/10.1002/2017JB014247

Zannat UJ, Tregoning P (2017b) Estimating network effect in geocenter motion: Theory. J Geophys Res Solid Earth 122(10):2017JB014,246. https://doi.org/10.1002/2017JB014246

Zwally HJ, Giovinetto MB, Li J, Cornejo HG, Beckley MA, Brenner AC, Saba JL, Yi D (2005) Mass changes of the Greenland and Antarctic ice sheets and shelves and contributions to sea-level rise: 1992-2002. J Glaciol 51(175):509-527 